\title{
Molecular Detection of Pseudomonas Aeruginosa Isolated From Chicken Cans in the Markets of Al-Muthanna Province
}

\author{
Shayma Abdullah Hanoon ${ }^{1}$, Ali Hasanain Alhamadani², Taisir Abdulelah Kadhim \\ ${ }^{1}$ Master of Pedodontics, Dentistry College/Al-muthanna University, ${ }^{2}$ Master of Physiology, Nursing College/Al- \\ Muthanna University, ${ }^{3}$ P.hd. Medical Microbiology, Nursing college/Al-Muthanna University
}

\begin{abstract}
Food safety is very necessary for the general health of the consumer and protection from disease, as well as the importance of economic sustain ability of the agricultural food sector. The consumer wants to make sure that the food is safe and that it is not contaminated with bacteria. Therefore, these tests must be performed to detect bacteria and ensure that food safety.

120 samples was collected from frozen chicken cans from the markets of Al-Muthanna province, using the sterile plastic bags and after isolation the results showed that (55) sample contain bacteria Pseudomonas aeruginosa from the total samples above.
\end{abstract}

The results of bacterial culture were positive in 45 samples whereas the results of direct molecular identification were positive in 55 samples.

Selective media used for bacteria identification such as MacConkey Agar, Methyle red which has been given the proportion of isolation ( $15 \%$ and $85 \%$ respectively) also some isolates showed their ability to liquefy gelatin (65\%) and fermented sugar lactose (100\%) . however biochemical testing also used for all bacterial isolates for confirm diagnoses.

Polymerase chain reaction technique used for detection bacteria by specific primers sequence the result appear $45 \%$ of total sample contamination by $P$. aeruginosa .

The genome of $P$. aeruginosa is relatively large so encodes a large proportion of regulatory enzymes important for metabolism and efflux of organic compounds. This enhanced coding capability genome allows for great metabolic versatility and high adaptability to environmental changes,

According our result we recommend food factories to use sterilized materials more accurately and effectively to store frozen chicken cans.

Keywords: P. aeruginosa, culture media, PCR technique, food safety, canned chicken.

\section{Introduction}

The general characteristics of bacteria Pseudomonas species are widely spread in soil, aquatic environment and normal flora in plants and animals. For example, Pseudomonas aeruginosa which is an opportunistic pathogen causes disease and is largely isolated from wounds, burns and urinary tract infections ${ }^{1}$. P.aeruginosa reduces the chances of successful tissue transplantation and causes septicemia for patients with burns and is associated with mortality These bacteria can be transmitted to other areas of the body. The most common is the inflammation of the heart of people who use intravenous drugs and who have artificial valves due to the need of bacteria directly to the bloodstream and that these bacteria cause bacteremia, especially in patients who suffer from immunodeficiency, HIV and diabetes and in cases Severe burns ${ }^{\mathbf{1}}$.

Pseudomonas aeruginosa is an opportunistic pathogen that is a leading cause of morbidity and mortality 
in cystic fibrosis patients and immunocompromised individuals ${ }^{2}$.

P.aeruginosa is a Gram-negative bacillus shape bacteria with a length of about 1-5 microns and its width (0.5-1). Micronized by monoflagellated monocytes does not have a Capsule that is not composed of aerobic spores and can grow in anaerobic conditions that cause common diseases of humans and animals found in soil Water, skin and plants, it is growing at a temperature above $42 \mathrm{~m}$ and has the potential to grow in diesel and fuel ${ }^{3,4}$. P.aeruginosa bacteria are opportunistic and the most common infections occur in patients who are hospitalized, as well as in immunosuppressed persons such as AIDS, cancer, cystic fibrosis, neutropenia and also the loss of mechanical barrier or protection (skin mucosa). And the symptoms of this infection is inflammation and poisoning and occurs in the body members critical such as lung and urinary tract and kidney and skin injury and thin tissue, where it was found that about $6 \%$ of people exposed to burns die of infection with this bacteria 5 . Laboratory diagnosis is based on the sampling of blood, cerebrospinal fluid, blood, pus and gosaibular secretions and then is implanted and tested ${ }^{6}$. P.aeruginosa bacteria, especially isolated from wounds and burns, have resistance to many antibiotics such as Gentamicin, Aztreonam, Ceftriaxone, Pipracillin, Ciprofloxacin, Tobramycin, Cefsulodine and Amikacion ${ }^{7,8,9,10}$

These bacteria are involved in serious infections that are difficult to treat and destroy due to their multiple antibiotic resistance. It is the most common cause of burn and wound injuries ${ }^{11}$. These bacteria cause contamination of wounds that lead to tissue breakdown and extrusion of blood plasma outside the skin a good place for bacterial growth ${ }^{12}$. As well as caused by bacteremia blood due to the arrival of the blood stream and then transmission of different tissues with a mortality rate of $30^{\mathbf{1 3}}$. The World Health Organization has recently listed carbapenemresistant $P$. aeruginosa as one of three bacterial species in which there is a critical need for the development of new antibiotics to treat infections ${ }^{14,15}$.

PCR has the potential for identifying microbial species rapidly by amplification of sequences unique to a particular organism that is outer lipoprotein membrane (oprL) gene ${ }^{16}$.

\section{Material and Method}

1. All sample are collected from various markets in AlMuthanna province.

2. Total of 120 tissue samples were taken from frozen chicken cans including the lung, liver and chest muscles in a sterile manner.

3. The samples were collected in sterile plastic bags and then sent to the laboratory.

4. The samples were crushed by a sterile ceramic vial and the starter was obtained and culture on test tube containing on nutrient agar then incubation at $37 \mathrm{c}$ for 24 hours.

\section{Prepare Culture Media:}

1. Were used Ashdown Selective broth media Add 10 grams of Trypton Soya Broth, $5 \mathrm{~g}$ of Pepton, $5 \mathrm{mg}$ of Crystal Violate and $50 \mathrm{mg}$ of Neutral Red to 1 liter of distilled water, add $40 \%$ Glycerin and heat with $\mathrm{pH}$ 7.2. Then sterilize and leave to cool down. $(40 \mathrm{~m})$ and then add antibiotic Colistin $(20 \mathrm{mg} / \mathrm{l})$ then preparation Ashdown`s Selective Agar (ASA) Prepare $40 \mathrm{ml}$ of Trypton soya agar, $5 \mathrm{mg}$ of Crystal Violate, 50 Neutral Neutral of red, 1 liter of distilled water, add $4 \%$ of Glycerin and heat with $\mathrm{pH}$ to $\mathrm{pH}$ 7.2. And then left to cool down (40) $\mathrm{m}$ then add antibiotic Gentamycin by $(4 \mathrm{mg} / \mathrm{l}){ }^{17}$.

2. Nutrient Agar and broth preparation according to Himedia company after adjusting the $\mathrm{pH}$ using a ph-meter and sterilized with autoclave. After that samples were cultured on ASB and incubated at 35 ${ }^{\circ} \mathrm{C}$ for 7 days until the color of the purple medium was changed and then cultured on the ASA using the loop in the Streaking method and incubated at $53{ }^{\circ} \mathrm{C}$ for 48 hours. ${ }^{18}$

3. Samples planted on the Ashdown selective broth, which gave the highest percentage of isolation of bacteria Pseudomonas aeruginosa $(100 \%)$ and then planted on the Ashdown selective agar where the percentage of isolation $(100 \%)$ was development and activate the colonies germ isolated from circles selective isolates through cultivation amid Neutrient agar which gave the percentage of isolation $(100 \%)$

4. biochemical diagnostic testing for all bacterial that isolates for example test production of the enzyme Catalase test as well as the production of the Oxidase enzyme which gave isolation rate $(100 \%)$ for both. 
- Molecular Detection

PCR assay for confirmation of Pseudomonas aeruginosa isolates.

1. DNA was extracted from samples by AccuPrep ${ }^{\circledR}$ Genomic DNA extraction kit (Bioneer, Korea).

2. PCR was performed on extracted DNA by using specific primer to oprL gene (Bioneer Company, Korea) were amplified according to references mentioned in table (1).

3. Primers were utilized in a $25 \mu \mathrm{l}$ reaction containing $12.5 \mu \mathrm{l}$ of AccuPowerTM PCR PreMix (Bioneer, Korea), $1 \mu \mathrm{l}$ of each primer of 20 pmol concentrations, $4.5 \mu \mathrm{l}$ of free nuclease water and 6 $\mu \mathrm{l}$ of the template ${ }^{\mathbf{1 9 , 2 0}}$

4. The reactions were performed in a BioRad, USA thermal cycler. PCR was performed using the protocol: $94^{\circ} \mathrm{C}$ for $5 \mathrm{~min}$, followed by 35 cycles of $94^{\circ} \mathrm{C}$ for $45 \mathrm{sec}, 50^{\circ} \mathrm{C}$ for one min and $72^{\circ} \mathrm{C}$ for one min, followed by $72^{\circ} \mathrm{C}$ for five min.

5. For gel analysis, $10 \mu \mathrm{l}$ of the products were loaded in each gel pit. PCR products were Imagine on $1 \%$ agarose gel electrophoresis (Consort, Belgium). ${ }^{21}$

Table (1): Specific primers sequence for detection P. aeruginosa.

\begin{tabular}{|l|c|c|c|}
\hline References & Amplicon (bp) & sequence (5'-3') & Target Gene \\
\hline (Xu et al., 2004) & bp 504 & F: ATG GAA ATG CTG AAA TTC GGC & \multirow{2}{*}{ oprL } \\
\hline
\end{tabular}

\section{Results}

Various investigations were carried out on frozen canned chicken samples which included 120 sample evenly taken from the heart, liver and chest muscles all samples tested by different media, molecular and biochemical tests, all Tests showed that 55 samples were contaminated with Pseudomonas aeruginosa bacteria. Firstly, all sample cultured on ASB media, positive isolates changed the color of the medium to a reddish brown color. The bacteria were then isolated on the selective media ASA at $35^{\circ}$. Result show 40 sample contaminated by $p$. aeruginosa was diagnosed from frozen canned chicken (14 of heart, 14 of chest muscles, 12 of liver) all isolated characterized by colonies as large colonies and dark brown and brown after a period 24-72 hours. The colonies also showed different appearance characteristics from a sticky to a grayish gray. To confirm the diagnosis of the bacteria was staining with Gram stain and appeared in the small bacillus in shape and gram-negative bacteria,

Secondly, molecular test carry out by used PCR technique for all samples was performed on extracted DNA by using specific primer to oprL gene, The results showed that 55 samples were contaminated with Pseudomonas aeruginosa .

Thirdly biochemical tests also carried out to positive sample which isolates from selective media ASA for confirm diagnoses, The results showed that all isolates were positive for the tests of catalase, phosphatase, oxides, growth at $37-42 \mathrm{~m}$ and the ability to grow on MacConky Agar and oxidation of lactose .

Table 2. Clarify Number of isolated and contaminated samples with P.aeruginosa from frozen canned chicken

\begin{tabular}{|c|l|c|c|c|c|}
\hline No & Type of sample & $\begin{array}{c}\text { Number of } \\
\text { sample }\end{array}$ & $\begin{array}{c}\text { Number of isolates by } \\
\text { culture media }\end{array}$ & $\begin{array}{c}\text { No of bacteria by } \\
\text { PCR technique }\end{array}$ & $\begin{array}{c}\text { Percentage of contamination in } \\
\text { all sample }\end{array}$ \\
\cline { 1 - 4 } 1 & Heart & 40 & 14 & 16 & \multirow{2}{*}{4} \\
\cline { 1 - 5 } 2 & Chest muscles & 40 & 14 & 21 & 18 \\
\hline 3 & Liver & 40 & 12 & $\mathbf{5 5}$ & $\mathbf{1 0 0 \%}$ \\
\hline $\mathbf{4}$ & Total & $\mathbf{1 2 0}$ & $\mathbf{4 0}$ & \\
\hline
\end{tabular}




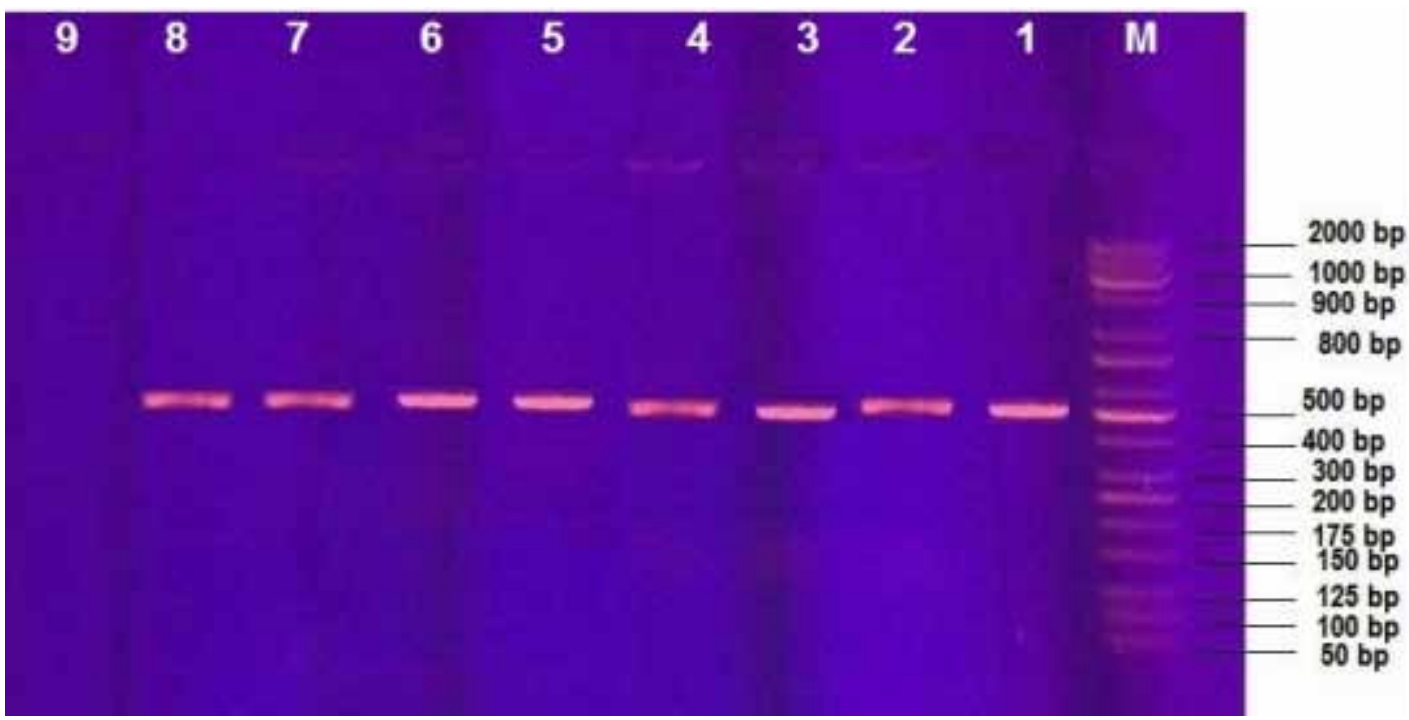

Figure 1. Agarose gel electrophoresis $1.5 \%$ for oprL PCR products, gel was electrophoresed for 1 hours at 70 Volt. The size of PCR product is 504 bp. All lanes show positive result except lanes 9.

\section{Discussion}

The results showed that $45 \%$ of the total examined samples were contaminated with bacteria Pseudomonas aeruginosa and this percentage proves the possibility and ability of $p$. aeruginosa to resist all sterilization conditions conducted by canned factories for frozen canned chicken, due to It has a genome (5.5-7 Mbp) is relatively large compared to other serial bacteria It encodes a large proportion of the regulatory enzymes important for metabolism, transport and flow of organic compounds. The improved coding power of the P. aeruginosa genome provides great metabolic ingenuity and high adaptability to environmental changes .

The results showed that there is a relative difference between the culture media and the molecular test, as it showed that the samples examined with PCR technique were diagnosed with $\mathrm{P}$. aeruginosa a little more compared to the diagnosis of the culture media and this difference depends on that PCR technique detect bacteria based on its gene even where the probability of the bacteria being Dead or weak, so it cannot grow in the culture media.

Result of positive samples that were diagnosed from canned samples of the heart, liver and muscles, we notice that the proportions were close between the samples contaminated with $P$. aeruginosa and this is due to the ability of bacteria to grow in all wet tissues and the ability of $P$. aeruginosa to tolerate different conditions. is able to survive in a wide range of environments.

In addition to the high level of intrinsic antibiotic resistance of $P$. aeruginosa, the acquired resistance greatly contributes to development of multidrug-resistant strains, which increases the difficulty in eradicating this microorganism and leads to more cases of persistent infections

Therefore, we recommend the food factories producing frozen chicken cans to take new sterilization and preservation method .

\section{Conflict of Interests: Nil.}

Ethical Clearance: Take from markets in $\mathrm{Al}$ Muthanna province by approval ethical committee.

Funding: Self-funding.

\section{References}

1. Zheng P, Renee R, Bernard R, Tong JL, Zhenyu C. Antibiotic resistance in Pseudomonas aeruginosa: mechanisms and alternative therapeutic strategies. Biotechnology Advances. 2019 January-February; 37(1):177-192

2. Silby M, Winstanley C, Godfrey S, Levy S, Jackson R. Pseudomonas genomes: diverse and adaptable. 
FEMS Microbiol Rev.2011; 35, 652-680.

3. Chen J, Chen Y, Hu P, Zhou T, Xu X, Pei X . Risk assessment of infected children with Pseudomonas aeruginosa pneumonia by combining host and pathogen predictors. Infect Genet. 2018 Jan; 57:82-87.

4. Zhang R1, Liu Z1, Li J1, Lei L1, Yin W1, Li M1, al, et al. Presence of VIM-Positive Pseudomonas Species in Chickens and Their Surrounding Environment. Antimicrob Agents Chemother. 2017 Jun 27;61(7).

5. Fekadu K. Pseudomonas infection in chickens. Journal of Veterinary Medicine and Animal Health .2010 Nov;2(4):55-58

6. Fekadu K. Standard Bacteriological Manual .MYCOGS.2005; 1

7. Gong Q, Ruan MD, Niu MF, Qin CL, Hou Y, Guo JZ1. Immune efficacy of DNA vaccines based on oprL and oprF genes of Pseudomonas aeruginosa in chickens.Poultry Science.2018 December 1;97(12):4219-4227

8. Jennings LK, Storek KM, Ledvina HE, Coulon C, Marmont LS, Sadovskaya I,et al . Pel is a cationic exopolysaccharide that cross-links extracellular DNA in the Pseudomonas aeruginosa biofilm matrix. Proc Natl Acad Sci U S A. 2015 Sep 8;112(36):11353-8

9. Balcht A, Smith R. Pseudomonas Aeruginosa: Infections and Treatment. Informa Health Care. 1994, 83-84.

10. Hassan H M. Characterization of Pseudomonas aeruginosa isolated from different pathological lesions in chickens. M.Microbiology.2013

11. Ahmed M, Sudhakar M, Senthil K, Molecular characterization of Pseudomonas sp. isolated from milk samples by using RAPD-PCR. European Journal of Experimental Biology.2014; 4(4):78-84

12. De Smet J, Hendrix H, Blasdel BG, Danis W K, Lavigne R. Pseudomonas predators: understanding and exploiting phage-host interactions.
Microbiology. 2017 September.; 15 (9):517-530. doi:10.1038/nrmicro. 2017.61. PMID 28649138.

13. Munita J.M, Arias C.A. Mechanisms of antibiotic resistance .Microbiol Spectr. 2016 Apr;4(2).

14. Tacconelli E, Carrara E, Savoldi A, Harbarth S, Mendelson M, Monnet DL,et al. Discovery, research and development of new antibiotics: the WHO priority list of antibiotic-resistant bacteria and tuberculosis. Lancet Infect Dis. 2018 Mar;18(3):318-327.

15. Cornelis P. Pseudomonas: Genomics and Molecular Biology . Caister Academic Press. 2008;19-6

16. Worlitzsch D, Tarran R, Ulrich M, Schwab U, Cekici A, Meyer KC, et al. Effects of reduced mucus oxygen concentration in airway Pseudomonas infections of cystic fibrosis patients. The Journal of Clinical Investigation. 2002February;109 (3):317 25. doi:10.1172/JCI13870. PMC

17. Dzidic S, Suskovic J, Kos B. Antibiotic Resistance Mechanisms in Bacteria: Biochemical and Genetic Aspects. Food Technology and Biotechnology.2008;46(1): 11-21.

18. Kitao T, Lepine F, Babloudi S, Walte F, Steinbacher $\mathrm{S}$, et al .Molecular insights into function and competitive inhibition of Pseudomonas aeruginosa multiple virulence factor regulator. MBio.2018

19. Khan A, Cerniglia C . Detection of Pseudomonas aeruginosa from clinical and environmental samples by amplification of the exotoxin A gene using PCR. Appl Environ Microbiol.1994;60:3739-3745

20. Itah A, Essien J. Growth Profile and Hydrocarbonoclastic Potential of Microorganisms Isolated from Tarballs in the Bight of Bonny. World Journal of Microbiology and Biotechnology. 2005;21 (6-7): 1317-22. doi:10.1007/s11274-0046694-z

21. Yi-Wei T, Max S, Ian P, Dongyou L, Joseph S. Molecular Medical Microbiology. Elsevier. 24th November 2014;3: Second Edition 